\title{
Internal Strains between Grains during Creep Deformation of an
}

Austenitic Stainless Steel

\author{
B. Chen ${ }^{\mathrm{a}, \mathrm{b},{ }^{*}, \text { J.N. Hu}}{ }^{\mathrm{c}}$, Y.Q. Wang ${ }^{\mathrm{a}}$, S. Kabra ${ }^{\mathrm{d}}$, A.C.F. Cocks ${ }^{\mathrm{c}}$, D.J. Smith ${ }^{\mathrm{a}}$, \\ P.E.J. Flewitt ${ }^{\mathrm{e}}$ \\ ${ }^{a}$ Department of Mechanical Engineering, University of Bristol, Bristol, BS8 1TR, UK \\ ${ }^{b}$ Materials Performance Centre, School of Materials, The University of Manchester, Manchester, \\ M13 9PL \\ ${ }^{c}$ Department of Engineering Science, University of Oxford, OX1 3PJ, UK \\ ${ }^{d} I S I S$, Science and Technology Facilities Council, Rutherford Appleton Laboratory, Chilton, Didcot, \\ Oxfordshire, OX11 OQX,UK \\ ${ }^{e}$ H.H. Wills Physics Laboratory, University of Bristol, Tyndall Avenue, Bristol, BS8 1TL, UK \\ ${ }^{*}$ Corresponding author. Tel.: +44 117331 5941. Fax: +44 1179294423. \\ E-mail address: bo.chen-2@manchester.ac.uk
}

\begin{abstract}
Internal strains that develop between grains during creep of an austenitic stainless steel were measured using in-situ neutron diffraction. The secondary creep prestrained test specimens were considered. Measurements were undertaken before, during and post creep deformation at $550{ }^{\circ} \mathrm{C}$. There was no measurable change of internal strains between grains during in-situ creep for $4 \mathrm{~h}$ at $550{ }^{\circ} \mathrm{C}$. In addition, the effect of increasing/reducing temperatures in a range from $470{ }^{\circ} \mathrm{C}$ to $550{ }^{\circ} \mathrm{C}$ on the internal strains was measured and interpreted with respect to contributions from thermal expansion/contraction. No further internal misfit strains between grains were created when specimen crept during the dwell time at $530{ }^{\circ} \mathrm{C}, 510^{\circ} \mathrm{C}, 490{ }^{\circ} \mathrm{C}$, and 470 ${ }^{\circ} \mathrm{C}$. Results are discussed with respect to (i) the general structure of self-consistent models and (ii) the optimised use of neutron sources for creep studies.
\end{abstract}

Keywords: Internal strains; Neutron diffraction; Creep; Crystal plasticity; Stainless steels

\section{Introduction}

When a polycrystalline material is deformed plastically and then unloaded, the presence of internal strains/stresses between grains is a consequence of elastic-plastic anisotropy at the length-scale of grains [1]. In-situ neutron diffraction is often used to measure these meso-scale internal strains/stresses in a bulk polycrystalline material 
[1-4]. The crystal plasticity finite element [5] or self-consistent models [1,4] developed at the length-scale of grains can be used to predict the bulk behaviour of a polycrystalline material. Self-consistent models, which provide information about the average response of different grain families, can be compared directly with neutron diffraction measurements. This approach aids the development of these models, while at the same time providing a physical interpretation of the experimental results. Experimental data to validate self-consistent models within the creep regime are limited [1,4,6-10]. For example, Ma et al. [10] studied internal stress evolution using in-situ neutron diffraction when a polycrystalline superalloy was creep deformed at $900{ }^{\circ} \mathrm{C}$ and a primary stress level of $425 \mathrm{MPa}$ for about $35 \mathrm{~h}$. The selection of such a high test stress and temperature seems to be limited by the availability of neutron beam time.

We report an in-situ neutron diffraction study to evaluate internal strains before, during and post creep deformation at a temperature of $550{ }^{\circ} \mathrm{C}$ for a Type $316 \mathrm{H}$ austenitic stainless steel. The secondary creep pre-strained specimens were measured using in-situ neutron diffraction. This avoids of undertaking a long term creep study at neutron diffraction facility to examine creep mechanism. In addition, the effect of temperature change on internal strains was studied. The results are examined in the context of the general structure of self-consistent models.

\section{Material and Experimental}

A Type $316 \mathrm{H}$ austenitic stainless steel extracted from a high temperature ex-service component was supplied by EDF Energy Nucleation Generation Ltd. The chemical composition of this material is given in Table 1. Its thermo-mechanical history includes plant service at temperatures between $490{ }^{\circ} \mathrm{C}$ to $530{ }^{\circ} \mathrm{C}$ for $65,015 \mathrm{~h}$, followed by thermal ageing at $550{ }^{\circ} \mathrm{C}$ for $22,100 \mathrm{~h}$. This material has been selected as one of the superheater header materials for the ongoing research project with a primary focus to meet the challenges for extending the lifetime of the UK's advanced gas cooled reactors (AGRs). The additional thermal ageing at $550{ }^{\circ} \mathrm{C}$ for $22,100 \mathrm{~h}$ was undertaken to simulate a material condition representative of that subjected to a longer term service exposure. The material used for the present study is essentially a single phase, face-centred-cubic (FCC) polycrystalline stainless steel, since the sizes of inter- and intra-granular carbide precipitates were measured to be $0.2 \mu \mathrm{m}$ and 0.03 
$\mu \mathrm{m}$ respectively [11]. This is corroborated by in-situ Bauschinger effect tests using the same material [4], where no second phase carbide precipitates induced permanent softening was observed. The grain size of the material was measured to be $87 \pm 9 \mu \mathrm{m}$ (linear intercept method).

Three uniaxial creep test specimens with a $28.25 \mathrm{~mm}$ gauge length and $5.65 \mathrm{~mm}$ diameter were manufactured; specimen conditions are summarised in Table 2. The gauge length of the creep test specimen is five times greater than its diameter, which meets the minimum requirement as given in [12]. Specimen 1 received no pre-strain. Specimens 2 and 3 were loaded to a maximum tensile stress of $250 \mathrm{MPa}$ at $550{ }^{\circ} \mathrm{C}$ and then allowed to creep for $1000 \mathrm{~h}$. Secondary creep was achieved for specimens 2 and 3 within a period of 1000 h, Figure 1. Following this creep pre-strain, specimens 2 and 3 were cooled to room temperature and unloaded elastically. The measured plastic pre-strains during specimen loading and creep pre-strains during the subsequent creep for $1000 \mathrm{~h}$ are shown in Table 2. The loading induced plastic prestrain in specimen 2 is smaller than that in specimen 3, while the creep pre-strain in specimen 2 is higher than that in specimen 3. This is consistent with the effect of prestrain upon specimen loading at $550{ }^{\circ} \mathrm{C}$ on the subsequent creep rate in Type $316 \mathrm{H}$ stainless steels, proposed by Wilshire and Willis [13].

Both ex-situ and in-situ neutron diffraction measurements were adopted using the ENGIN-X instrument, ISIS, UK. The former provides a measure of the internal strains created by the secondary creep pre-strain, whereas the latter was performed during tensile creep deformation. Both the ENGIN-X neutron diffractometer and the in-situ testing rig have been described in detail elsewhere $[3,9,14,15]$. Each specimen was positioned in a $100 \mathrm{kN}$ testing rig, where the load frame (i.e. the axial direction of the specimen) was orientated at an angle of $45^{\circ}$ relative to the incident neutron beam. A neutron detector located at $90^{\circ}$ to the incident beam provided the measurement of axial internal strain. The bisector between the incident and diffracted beams was along the axial direction of the specimen. This ENGIN-X testing rig was equipped with a radiant furnace for heating the specimen to the pre-defined temperature for the in-situ tensile creep deformation. The macro-strain of the bulk specimen was measured using a high temperature extensometer.

For the evaluation of the internal strains created by secondary creep pre-strain (exsitu neutron diffraction measurement), the measured lattice spacing along the axial direction of specimens 2 and 3 were compared with that measured in specimen 1. 
Specimen 1 received no pre-strain and was the reference for specimens 2 and 3, Table 2. The axial internal strain was calculated from the relative change of the lattice spacing for the specific $\{h k l\}$ grain family [3]. Such a diffraction peak shift analysis provides a measure of internal strain at the length-scale of the family of grains. More details about the principles of neutron diffraction technique for measuring internal strains can be found elsewhere [16]. Four grain families were measured: $\{111\}$, $\{200\},\{220\}$ and $\{311\}$. A single peak fitting routine was used to determine the specific lattice spacing [14].

The secondary creep pre-strained specimens 2 and 3 were then subjected to in-situ neutron diffraction, Table 2. In this case, the "reference" lattice spacing for each grain family was taken as the initially measured lattice spacing when the specimen was held at an applied stress of $5 \mathrm{MPa}$. This allowed evaluation of the internal strain created by the in-situ deformation at $550{ }^{\circ} \mathrm{C}$. The creep pre-strained specimen 2 was subjected to two in-situ testing cycles. Cycle 1 included the following steps: heat to $550{ }^{\circ} \mathrm{C}$, load to an engineering stress of $250 \mathrm{MPa}$, creep for $4 \mathrm{~h}$, cool and finally unload as shown in Figure 2 (a). The engineering stress was calculated from the original cross-section area of the specimen. After specimen 2 was unloaded at room temperature, it was subjected to cycle 2, Figure 2 (b). It was heated to $550{ }^{\circ} \mathrm{C}$ and then loaded to 250 $\mathrm{MPa}$. This was followed by creep and temperature changes at the same stress level of $250 \mathrm{MPa}$, by either increasing or reducing the temperature, Figure 2 (b). For cycle 2 the following temperatures were selected: $530^{\circ} \mathrm{C}, 510^{\circ} \mathrm{C}, 490{ }^{\circ} \mathrm{C}, 470{ }^{\circ} \mathrm{C}$ as well as the "reference temperature" of $550{ }^{\circ} \mathrm{C}$. These temperatures represent those experienced by the Type $316 \mathrm{H}$ stainless steels during service of AGRs in the UK. The test duration of cycle 1 was about $\sim 13 \mathrm{~h}$ and that for cycle 2 was $\sim 20 \mathrm{~h}$, Figures 2 (a) and (b). Since specimen 2 was previously subjected to secondary creep pre-strain for $1000 \mathrm{~h}$, cycle 1 can be judged to be a continuation of secondary creep. To examine the reproducibility of the specimen response when subjected to creep and temperature changes, specimen 3 was subjected to cycle 2 only, Table 2 .

A gauge volume of $3 \mathrm{~mm} \times 3 \mathrm{~mm} \times 4 \mathrm{~mm}$ was used to measure the lattice spacing and a typical measurement time of $600 \mathrm{~s}$ was selected to ensure good counting statistics for the diffraction peaks. This selected measurement time allowed at least six individual internal strain measurements to be undertaken during a creep dwell time of 1 h. During heating, Figures 2 (a) and (b), measurements were undertaken by holding the temperature constant for each step. During loading, Figures 2 (a) and (b), 
measurements were undertaken with stress-controlled holds for the elastic region and strain-controlled holds for the plastic region. Finally, during unloading, measurements were undertaken with stress-controlled holds for each step, Figures 2 (a) and (b).

Crystallographic texture was measured on a previously creep pre-strained Type $316 \mathrm{H}$ stainless steel specimen using the GEM instrument at ISIS neutron source. GEM has a large number of detectors covering a significant solid angle around the specimen. These detectors are bunched in 160 groups with each of the 160 energy dispersive patterns containing a number of diffraction peaks. The patterns are analysed simultaneously using the MAUD software [17] which contains the texture model. Details of texture measurements on GEM can be found in reference [18].

\section{Results}

Figure 3 (a) summarises the axial internal strains introduced by loading and creep pre-strain of $1000 \mathrm{~h}$ for specimens 2 and 3, compared with the non-pre-strained specimen 1 (zero internal strains), Table 2. Tensile internal strains were present in the $\{200\}$ grain family, whereas these strains were compressive for both the $\{220\}$ and $\{111\}$ grain families, Figure 3 (a). Small compressive internal strains were associated with the $\{311\}$ grain family. The absolute internal strain difference between specimens 2 and 3 introduced by high temperature pre-strain, $\Delta \varepsilon_{h k l}$, was $<170 \times 10^{-6}$ for all four grain families, Figure 3 (a). These differences could be due to the specimen-to-specimen variation for the creep tests, see the levels of plastic and creep pre-strains in Table 2. Since specimen 2 was unloaded at the finishes of both cycles 1 and 2, as indicated by steps 5 and 10 in Figure 3 (b), the internal strains created by subjecting the specimen to both cycles 1 and 2 can be evaluated. Although the measured creep macro-strains were $0.55 \%$ for step 5 of cycle 1 , and $1.43 \%$ for step 10 of cycle 2, Figure 3 (b), there were insignificant changes in the internal strains corresponding to all four grain families in the unloaded state, indicating that the internal misfit stresses between grains have not changed.

As shown in steps 2 and 7 of Figure 3 (b), in-situ neutron diffraction measurements were undertaken at incrementally increasing loads for specimen 2. There was little deviation from linearity in the measured axial internal strain when plotted against the 
applied stress ${ }^{1}$. This indicates that no extra internal misfit stresses were created by insitu loading of specimen 2 to resume the secondary creep deformation. Specimen 2 was subsequently subjected to in-situ creep for $4 \mathrm{~h}$ at $550^{\circ} \mathrm{C}$, as shown in Figure 2 (a) and step 3 of Figure 3 (b). During the range of creep deformation, approximately 20 neutron diffraction internal strain measurements were carried out, as shown in Figure 4 (a). Also shown in this figure is the creep strain (macro-strain) measured by the high temperature extensometer. The change of the axial internal strain during creep was calculated by comparing the axial internal strain at each creep time interval with that measured at the start of creep. This applies for all four grain families considered: $\{111\},\{200\},\{220\}$ and $\{311\}$. There were only small changes in the measured internal strains during creep, although the creep macro-strain increased linearly with time, Figure 4 (a). In addition, the derived creep rate from the in-situ creep test conducted at $550{ }^{\circ} \mathrm{C}$ and $250 \mathrm{MPa}$, as shown in Figure 4 (a), is two orders of magnitude higher than that from the creep pre-straining test undertaken at the same condition, as shown in Figure 1. This could be related to the dislocation recovery that would occur when the creep pre-strained specimen 2 was cooled to room temperature and unloaded elastically.

When specimen 2 was subjected to in-situ creep and temperature changes, Figure 2 (b), the changes of the axial internal strains during creep for $\sim 1 \mathrm{~h}$ were quantified for different temperatures: $530{ }^{\circ} \mathrm{C}, 510{ }^{\circ} \mathrm{C}, 490{ }^{\circ} \mathrm{C}, 470{ }^{\circ} \mathrm{C}$, and $550{ }^{\circ} \mathrm{C}$; examples are shown in Figures 4 (a) to (d). First, the creep rate decreased with the reduction in temperature; see the slopes of the macro-strain in Figures 4 (b) and (c). Second, there was a good agreement for the measured macro-strain at $550{ }^{\circ} \mathrm{C}$ for the initial and final creep, Figures 4 (a) and (d), where a creep macro-strain of $0.15 \%$ was achieved after $1 \mathrm{~h}$ at $550{ }^{\circ} \mathrm{C}$. Thus, there was no measurable change in the macroscopic response of the material after being subjected to cycle 2. Third, within the scatter of the measurement data, there was no systematic change in the axial internal strains during creep, Figures 4 (a) to (d). This indicates that the internal strains created by the crystallographic misfit between grains are independent of creep strain/time within the secondary creep condition. The uncertainty in the determined peak position was less than $6 \times 10^{-5} \AA$ and this corresponds with an uncertainty in the measured internal strain of $\pm 30 \times 10^{-6}$, as illustrated in Figure 4 (a). This magnitude

\footnotetext{
${ }^{1}$ The deviation from linearity results are not shown in this short communication
} 
of uncertainty applies similarly to the measurements of all four grain families: $\{111\}$, $\{200\},\{220\}$ and $\{311\}$. Any contribution from plastic strain in the width of the diffraction peak was not evaluated since the time-of-flight peaks have a more complex shape, i.e. a non-Gaussian diffraction peak shape measured at ENGIN-X [14].

The ex-situ neutron diffraction technique was used by Chen et al. [3,4] to measure the internal strains/stresses between grains for several creep pre-strained conditions; tests were interrupted at different levels of inelastic strain. When secondary creep was achieved, internal strains/stresses tended to a limiting value. Thus the present in-situ measurements are consistent with the previous work [3,4]. Finally, we observed similar changes for internal strains and the macro-strains during in-situ creep of specimen 3; thus the measurement is reproducible.

\section{Discussion}

To provide further insight into the internal strains between grains measured by insitu neutron diffraction, the general framework of self-consistent models is now described briefly. More details about the theory of self-consistent models can be found elsewhere [19-22]. In general, self-consistent models incorporate the crystal plasticity framework that provides an approximate procedure for calculating the plastic shear strain rate of each individual slip system in each grain, as well as the overall nominal plastic strain rate of each individual grain within a polycrystal [19]. Let $\dot{\gamma}^{(k)}$ denote the plastic shear strain rate on the $k$ th slip system of each individual grain. The relationship between $\dot{\gamma}^{(k)}$ and the resolved shear stress $\tau^{(k)}$ on the $k$ th slip system is taken as:

$$
\dot{\gamma}^{(k)}=\dot{\gamma}_{0}\left(\tau^{(k)} / \boldsymbol{\tau}_{c}^{(k)}\right)^{n}
$$

where $\dot{\gamma}_{0}$ is a reference creep rate and $\boldsymbol{\tau}_{c}^{(k)}$ is the critical resolved shear strength of the $k$ th slip system, which relates with the internal resistance to inelastic deformation and $n$ is the rate-sensitivity exponent. Change of the internal resistance is related to the evolution of different microstructural elements, such as hardening and recovery of dislocation network. In addition, the nominal plastic strain rate $\dot{\varepsilon}^{p}$ can be obtained by 
summing all the shear strain rates $\dot{\gamma}^{(k)}$ on all the active slip systems within the grain:

$$
\dot{\varepsilon}^{p}=\sum_{k} \theta^{(k)} \dot{\gamma}^{(k)}
$$

where $\theta^{(k)}$ is the Schmid factor of the $k$ th slip system which also links the resolved shear stress $\tau^{(k)}$ with the stress state of the individual grain.

The overall plastic strain rate of the bulk polycrystal $\overline{\dot{\varepsilon}}^{p}$ is regarded as the average of plastic strain rates $\dot{\varepsilon}^{p}$ over the volume $V$ of the polycrystal, i.e. the average over all individual grains, which can be determined using a virtual work principle [22]. This requires that the polycrystal is homogeneous (texture-free) at the macroscopic lengthscale. It is recognised that austentic stainless steels with a coarse grain size can have significant crystallographic texture. However Figure 6 shows that the present creep pre-strained Type $316 \mathrm{H}$ stainless steel specimen has a weak texture with none of the major crystal directions exceeding 1.4 times randomness in three crystallographic orientations $\{111\},\{200\}$ and $\{220\}$. Thus the assumption made for texture-free polycrystal considered in our work is reasonable.

The internal strains (misfit strains) between grains accumulate during macroscopic plastic deformation of the polycrystal. This accounts for the creation of Type II internal stresses (also called as Type II residual stresses) in grain/grain family lengthscales [23]. Such a misfit strain rate $\dot{\varepsilon}^{m}$ between an individual grain and the surrounding matrix in a polycrystal has been considered by Kroner [24], Budiansky and $\mathrm{Wu}[25]$ to be:

$$
\dot{\varepsilon}^{m}=\dot{\varepsilon}^{p}-\overline{\dot{\varepsilon}}^{p}
$$

Thus apart from the macroscopic stress applied to a polycrystal, internal stresses between grains also exist with a magnitude that varies depending on the grain orientations. The self-consistent models suggest that suitable steady state of internal stresses are established in the secondary creep. This condition results in all the grains in the polycrystal creeping compatibly $[19,20]$, i.e. the misfit strain rate in Eq. (3) as well as the internal strain/stress of each individual grain ceases to change. As a result, during secondary creep of a Type $316 \mathrm{H}$ austenitic stainless steel under a constant 
macroscopically applied stress, the internal strain/stress state in each individual grain remains constant. This accounts for the constant internal strains measured in the present work, such as Figure 4 (a).

In addition, the neutron diffraction measured internal strains changed insignificantly during a dwell at constant applied stress of $250 \mathrm{MPa}$ following a temperature change, as shown in Figures 4 (b) and (c). This could be a consequence of two possibilities. First, the stress dependence of the constitutive response of the grains changes weakly with temperature for the secondary creep condition, i.e. the mechanism of deformation does not change. Second, the constitutive response of the grains changes in a similar way with their surrounding matrix in a polycrystal, i.e. no further internal strains (misfit strains) create between the grains and the surrounding matrix.

There are two major contributions to the internal strains associated with the temperature change: (i) the thermal expansion (contraction) of the material and (ii) the temperature dependence of the elastic moduli. The internal strains due to the temperature changes occurring over cycle 2 for specimen 2 are shown in Figure 5. Since Type $316 \mathrm{H}$ stainless steel is a single phase polycrystalline material, the temperature change induced internal strain is isotropic. Four grain families are considered here and the measured internal strains are plotted against the accumulated macro-strain during cycle 2 as shown in Figure 5. The vertical axis represents the change in internal strain due to a temperature increase (positive) and decrease (negative). At each temperature, the absolute change of the internal strain is the same for a temperature increase and decrease for all the grain families, Figure 5, indicating that the response is reversible. In addition, there is a small difference among four grain families for each temperature change.

The magnitude of thermal expansion (contraction) induced internal strains was calculated by the product of temperature change and the thermal expansion coefficient, $\alpha=20 \times 10^{-6} /{ }^{\circ} \mathrm{C}[26]$. There is a small temperature dependence of $\alpha$ that has not been taken into account. The predicted internal strains shown in Figure 5 for both the thermal expansion and contraction are the same for all grain families and account for more than $90 \%$ of the measured internal strains due to temperature change. The measured internal strains deviate from the prediction with increasing temperature change, due to a contribution from the temperature dependent elastic moduli. Diffraction elastic constants for the different grain families, were determined 
from the in-situ room temperature neutron diffraction measurements [4] $-E_{111}=250$ $\mathrm{GPa}, E_{200}=160 \mathrm{GPa}, E_{220}=219 \mathrm{GPa}$ and $E_{311}=188 \mathrm{GPa}$. According to the temperature dependence of the elastic modulus, provided by Frost and Ashby [27], a temperature increase from $470{ }^{\circ} \mathrm{C}$ to $550{ }^{\circ} \mathrm{C}$ introduces additional internal strains $\varepsilon_{h k l}$ of: $84 \times 10^{-6}$ for $\{200\}, 61 \times 10^{-6}$ for $\{220\}, 54 \times 10^{-6}$ for $\{111\}$, and $71 \times 10^{-6}$ for $\{311\}$. The small difference between these values combined with any temperature dependence of $\alpha$ would contribute to the discrepancy between the measured and predicted values.

Finally, it is worthwhile to emphasise that the creep damage due to cavitation and associated micro-cracking are non-steady processes which subsequently modify secondary creep $[19,28]$. Since the present work is limited to the early stage of secondary creep, the influence of the creep damage on the neutron diffraction measured internal strains is judged to be negligible.

\section{Concluding Remarks}

In conclusion, in-situ creep combined with neutron diffraction measurements undertaken on a Type $316 \mathrm{H}$ austenitic stainless steel showed no measurable change of internal strains during secondary creep at the grain family length-scale. These results covered temperatures in the range from $470{ }^{\circ} \mathrm{C}$ to $550{ }^{\circ} \mathrm{C}$, demonstrating that no further internal strain between grains is created when secondary creep was achieved. The present measurements imply that it might not be necessary to undertake a continuous measure of internal strains within secondary creep for long-term creep studies of a single phase polycrystalline material, provided significant microstructural changes don't occur over the timescale of interest. 


\section{Acknowledgements}

Bo Chen and Jia Nan Hu are grateful to EDF Energy Nucleation Generation Ltd. for financial support. David Smith is supported by the Royal Academy of Engineering, EDF Energy and Rolls Royce plc. Peter Flewitt acknowledges Wolfson College, University of Oxford, for facilitating the collaboration.

\section{References}

1. Clausen B, Lorentzen T, Leffers T (1998) Self-consistent modelling of the plastic deformation of FCC polycrystals and its implications for diffraction measurements of internal stresses, Acta Mater 46:3087-3098

2. Daymond MR, Bouchard PJ (2006) Elastoplastic deformation of 316 stainless steel under tensile loading at elevated temperatures, Metall Mater Trans A 37:1863-1873

3. Chen B, Hu JN, Flewitt PEJ, Smith DJ, Cocks ACF, Zhang SY (2014) Quantifying internal stress and internal resistance associated with thermal ageing and creep in a polycrystalline material, Acta Mater 67:207-219

4. Chen B, Hu JN, Wang YQ, Zhang SY, Van Petegem S, Cocks ACF, Smith DJ, Flewitt PEJ (2015) Role of the misfit stress between grains on the Bauschinger effect for a polycrystalline material, Acta Mater 85:229-242

5. Li DF, O'Dowd N (2011) On the evolution of lattice deformation in austenitic stainless steels-The role of work hardening at finite strains, J Mech Phys Solids 59:2421-2441

6. Agnew SR, Brown DW, Tome CN (2006) Validating a polycrystal model for the elastoplastic response of magnesium alloy AZ31 using in situ neutron diffraction, Acta Mater 54:4841-4852

7. Korsunsky AM, James KE, Daymond MR (2004) Intergranular stresses in polycrystalline fatigue: diffraction measurement and self-consistent modelling, Eng Fract Mech 71:805-812

8. Winand HMA, Whitehouse AF, Withers PJ (2010) An investigation of the isothermal creep response of Al-based composites by neutron diffraction, Mater Sci Eng A 284:103-113

9. Rao A, Bouchard PJ, Northover SM, Fitzpatrick ME (2012) Anelasticity in austenitic stainless steel, Acta Mater 60:6851-6861

10. Ma S, Brown D, Bourke MAM, Daymond MR, Majumdar BS (2005) Microstrain evolution during creep of a high volume fraction superalloy, Mater Sci Eng A 399:141-153

11. Chen B, Flewitt PEJ, Smith DJ, Jones CP (2011) An improved method to identify grain boundary creep cavitation in $316 \mathrm{H}$ austenitic stainless steel, Ultramicroscopy 111:309-313

12. Webster GA, Holdsworth SR, Loveday MS, Nikbin K, Perrin IJ, Purper H, Skelton RP, Spindler MW (2004) A code of practice for conducting notched bar creep tests and for interpreting the data, Fatigue Fract Engng Mater Struct 27:319-342

13. Wilshire B, Willis M (2004) Mechanisms of strain accumulation and damage development during creep of prestrained 316 stainless steels, Metall Mater Trans A 35:563-571

14. Santisteban JR, Daymond MR, James JA, Edwards L (2006) ENGIN-X: a third-generation neutron strain scanner, J Appl Cryst 39:812-825

15. Chen B, Flewitt PEJ, Smith DJ (2010) Microstructural sensitivity of $316 \mathrm{H}$ austenitic stainless steel: Residual stress relaxation and grain boundary fracture, Mater Sci Eng A 527:7387-7399

16. Hutchings MT, Withers PJ, Holden TM, Lorentzen T (2005) Introduction to the Characterisation of Residual Stress by Neutron Diffraction. Taylor\&Francis, Boca Raton

17. Lutterotti L, Matthies S, Wenk HR MAUD (Material Analysis Using Diffraction): a user friendly Java program for Rietveld texture analysis and more. In: Proceeding of the Twelfth International Conference on Textures of Materials (ICOTOM-12), Vol. 1, Ottowa, Canada. NRC Research Press, 1999.

18. Kockelmann W, Chapon LC, Radaelli PG (2006) Neutron texture analysis on GEM at ISIS, Physica B 385-386:639-643

19. Hutchinson JW (1976) Bounds and self-consistent estimates for creep of polycrystalline materials, Proc Roy Soc Lond A 348:101-127 
20. Cocks ACF, Ponter ARS (1991) Constitutive equations for the plastic deformation of solids. II. A composite model, Eur J Mech 10:351-369

21. Wang H, Wu PD, Tome CN, Huang Y (2010) A finite strain elastic-viscoplastic self-consistent model for polycrystalline materials, J Mech Phys Solids 58:594-612

22. Hu JN, Cocks ACF (2015, Under Review) A multi-scale self-consistent model describing the lattice deformation in austenitic stainless steels, Int J Solids Struct

23. Chen B, Flewitt PEJ, Cocks ACF, Smith DJ (2015) A review of the changes of internal state related to high temperature creep of polycrystalline metals and alloys, Int Mater Rev 60:1-29

24. Kroner E (1961) On the plastic deformation of polycrystals, Acta Metall Mater 9:155-161

25. Budiansky B, Wu TT (1962) Theoretical prediction of plastic strains of polycrystals. In: Proc. 4th Congr. Appl. Mech. pp 1175-1185.

26. Thermophysical Properties of Materials for Nuclear Engineering: A Tutorial and Collection of Data (2008) International Atomic Energy Agency, Vienna, Austria. http://wwwpub.iaea.org/MTCD/publications/PDF/IAEA-THPH web.pdf. Accessed 12 Dec 2014

27. Frost HJ, Ashby MF (1982) Deformation-mechanism Maps. Pergamon, Exeter

28. Kassner ME, Hayes TA (2003) Creep cavitation in metals, Int J Plast 19:1715-1748 


\section{Figure Captions}

Figure 1 Creep strains during the creep tests of specimens 2 and 3 for $1000 \mathrm{~h}$ at $550{ }^{\circ} \mathrm{C}$ under an engineering stress of $250 \mathrm{MPa}$. The determination of secondary creep rate for specimen 2 is given for illustration.

Figure 2 Macro-strain and temperature history of specimen 2: (a) cycle 1 - heat, load, creep, cool and unload steps; (b) cycle 2 - heat, load, creep, temperature change, cool and unload steps. Note: Creep stress was kept at $250 \mathrm{MPa}$ over the temperature changes in cycle 2.

Figure 3 (a) Axial internal strain introduced by $1000 \mathrm{~h}$ creep pre-strain; (b) changes of macro-strain and axial internal strain for cycles 1 and 2 of Figure 2.

Figure 4 Evolution of internal strain and macro-strain during in-situ creep deformation of specimen 2 during different dwell steps of Figure 2 (b): (a) step $3-550^{\circ} \mathrm{C}$; (b) step $8-510{ }^{\circ} \mathrm{C}$; (c) step $8-470{ }^{\circ} \mathrm{C}$; (d) end of step $8-550{ }^{\circ} \mathrm{C}$. Note: The measurement uncertainty for internal strain has been indicated in Figure 4 (a). In-situ creep was carried out at a constant stress of $250 \mathrm{MPa}$.

Figure 5 Internal strain changes (measured and predicted) due to temperature change as a function of the accumulated macro-strain during cycle 2 of Figure 2 (b).

Figure 6 Crystallographic texture was measured on a creep pre-strained Type 316H austenitic stainless steel specimen using GEM instrument at ISIS neutron source, showing a weak texture for $\{111\},\{200\}$ and $\{220\}$ crystallographic orientations. Note: this specimen was creep tested for $60 \mathrm{~h}$ at $550{ }^{\circ} \mathrm{C}$ and $250 \mathrm{MPa}$, which produced a plastic pre-strain of $3.2 \%$ and a creep pre-strain of $1.1 \%$. 
Tables

Table 1. Chemical composition (wt.\%) of Type 316H stainless steel

\begin{tabular}{ccccccccccc}
\hline $\mathrm{C}$ & $\mathrm{Si}$ & $\mathrm{Mn}$ & $\mathrm{P}$ & $\mathrm{S}$ & $\mathrm{Cr}$ & $\mathrm{Mo}$ & $\mathrm{Ni}$ & $\mathrm{Co}$ & $\mathrm{B}$ & $\mathrm{Fe}$ \\
\hline 0.06 & 0.4 & 1.98 & 0.021 & 0.014 & 17.17 & 2.19 & 11.83 & 0.10 & 0.005 & Bal. \\
\hline
\end{tabular}

Table 2. Summary of high temperature pre-strain history given to the specimens which were then used for in-situ neutron diffraction study

\begin{tabular}{cccccc}
\hline $\begin{array}{c}\text { Specimen } \\
I D\end{array}$ & $\begin{array}{c}\text { Pre-strain }\left(550^{\circ} \mathrm{C}\right. \\
\text { and 250 MPa) }\end{array}$ & $\begin{array}{c}\text { Plastic pre- } \\
\text { strain, } \%\end{array}$ & $\begin{array}{c}\text { Creep pre- } \\
\text { strain, } \%\end{array}$ & \multicolumn{2}{c}{ In-situ neutron diffraction } \\
\cline { 6 - 7 } & No pre-strain & 0 & 0 & $\times$ & Cycle 1 \\
\hline 1 & Creep 1000h & 2.3 & 8.0 & $\sqrt{ }$ & $\sqrt{ }$ \\
\hline 2 & Creep 1000h & 2.6 & 7.2 & $\times$ & $\sqrt{ }$ \\
\hline 3 &
\end{tabular}


Figures

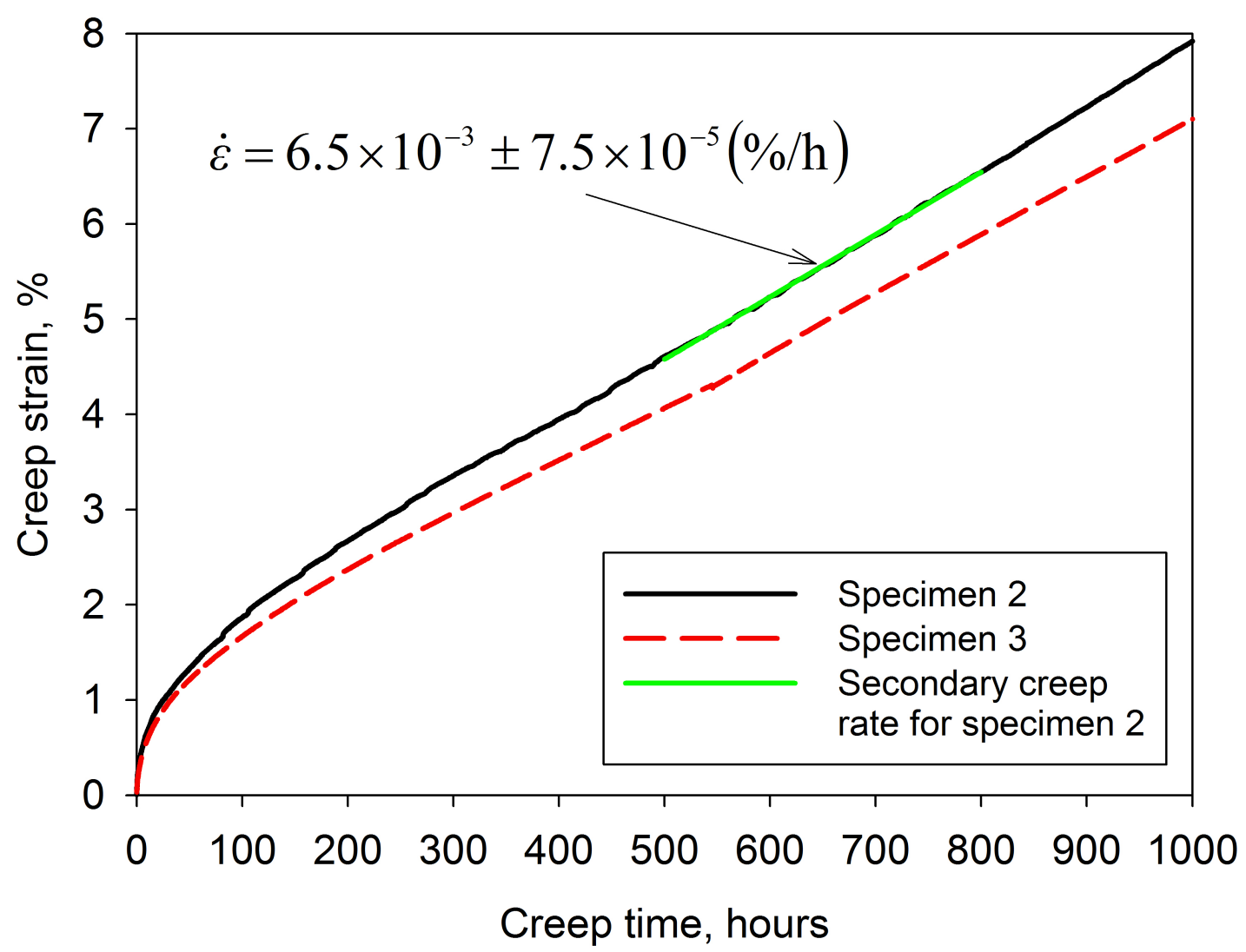

Figure 1: Creep strains during the creep tests of specimens 2 and 3 for $1000 \mathrm{~h}$ at 550 ${ }^{\circ} \mathrm{C}$ under an engineering stress of $250 \mathrm{MPa}$. The determination of secondary creep rate for specimen 2 is given for illustration. 


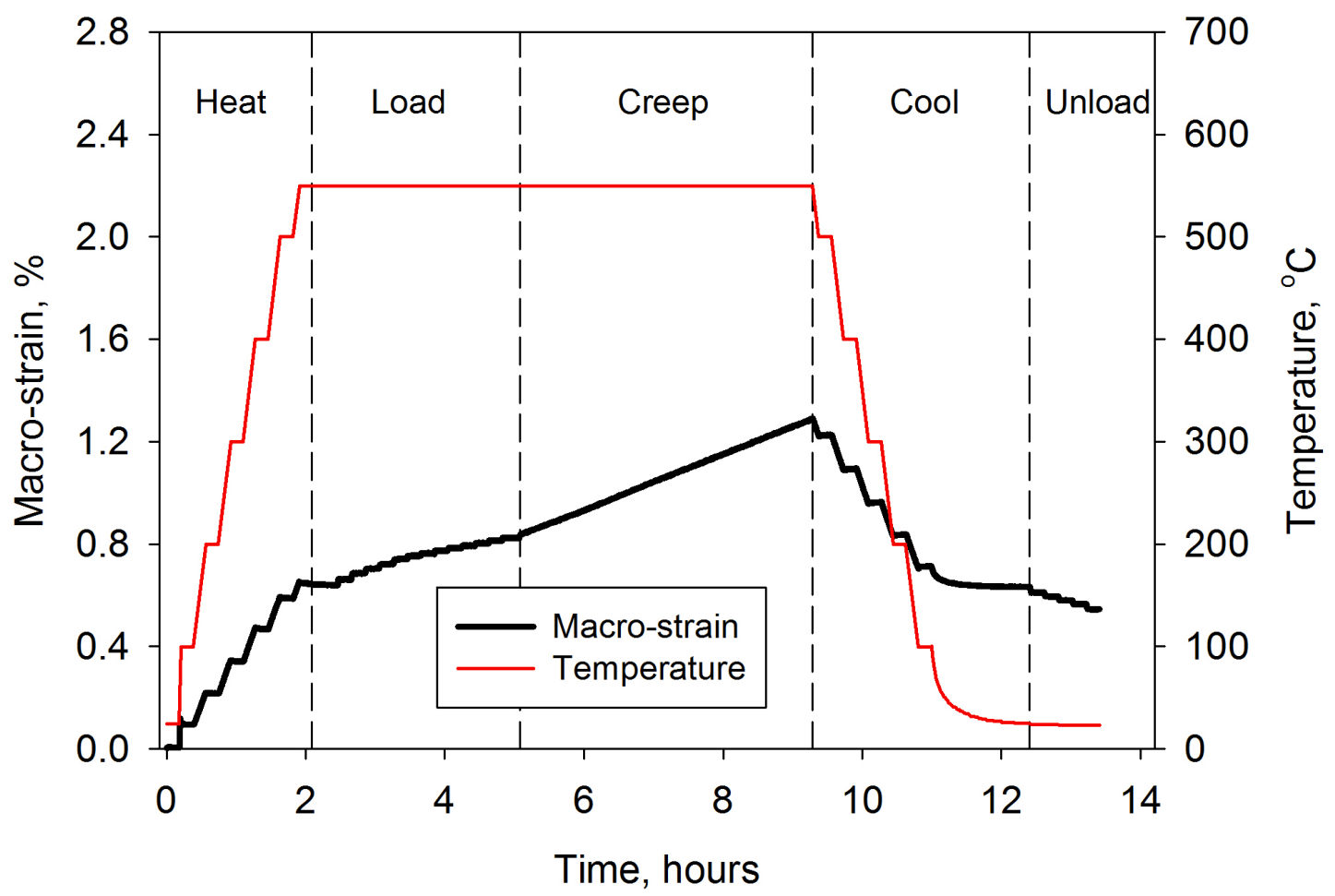

(a)

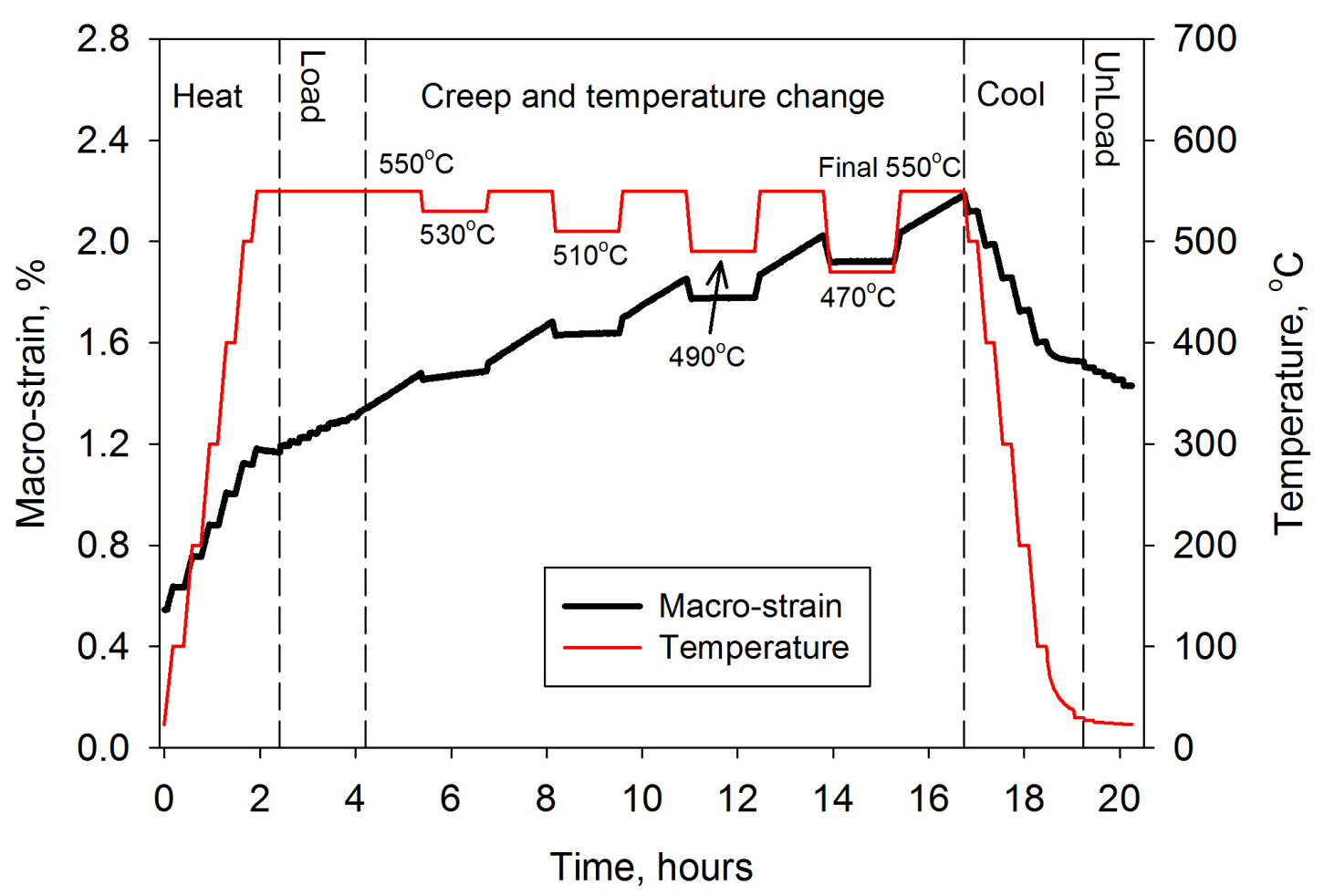

(b)

Figure 2: Macro-strain and temperature history of specimen 2: (a) cycle 1 - heat, load, creep, cool and unload steps; (b) cycle 2 - heat, load, creep, temperature change, cool and unload steps. Note: Creep stress was kept at $250 \mathrm{MPa}$ over the temperature changes in cycle 2. 


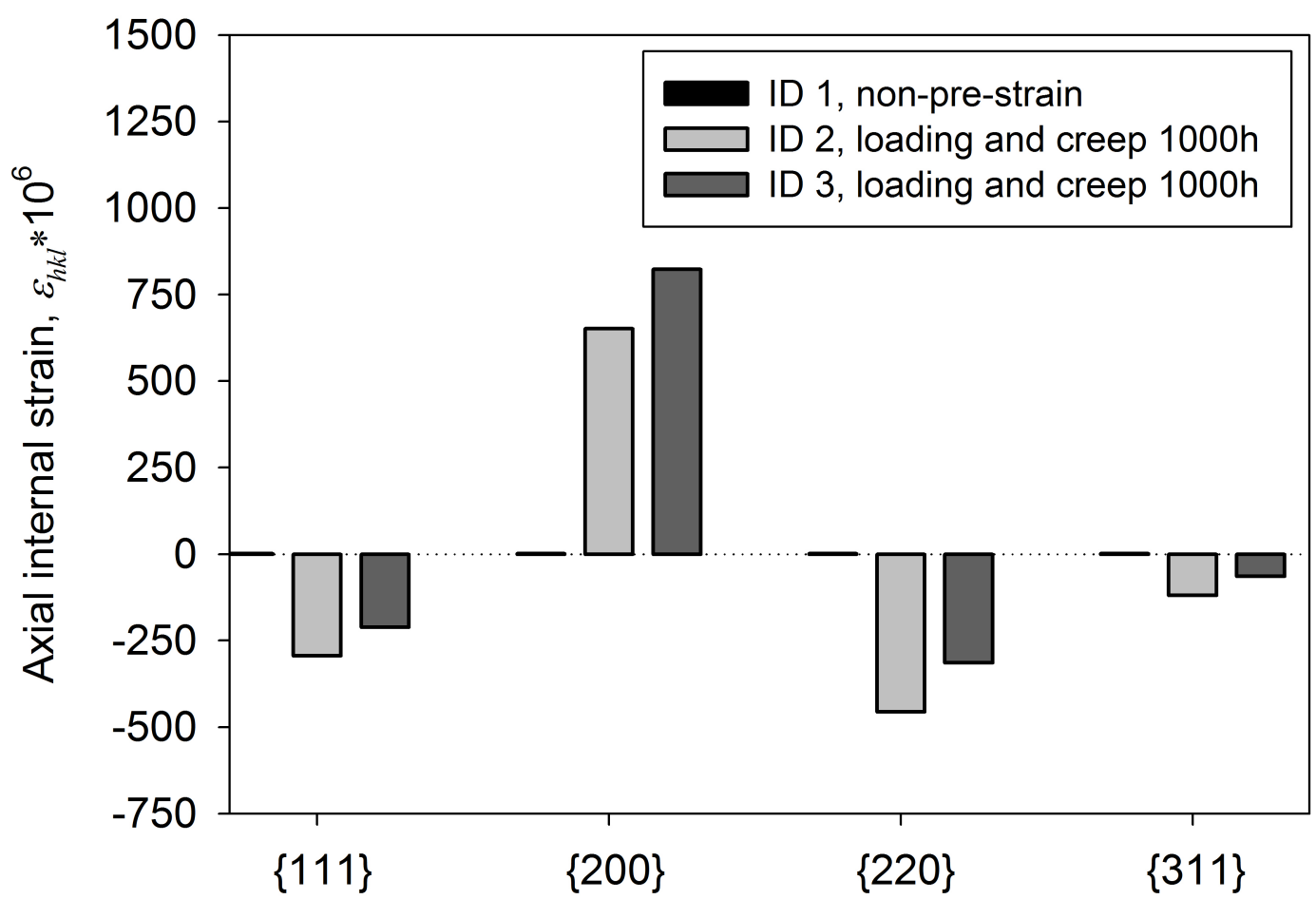

Selected grain families for neutron diffraction

(a)

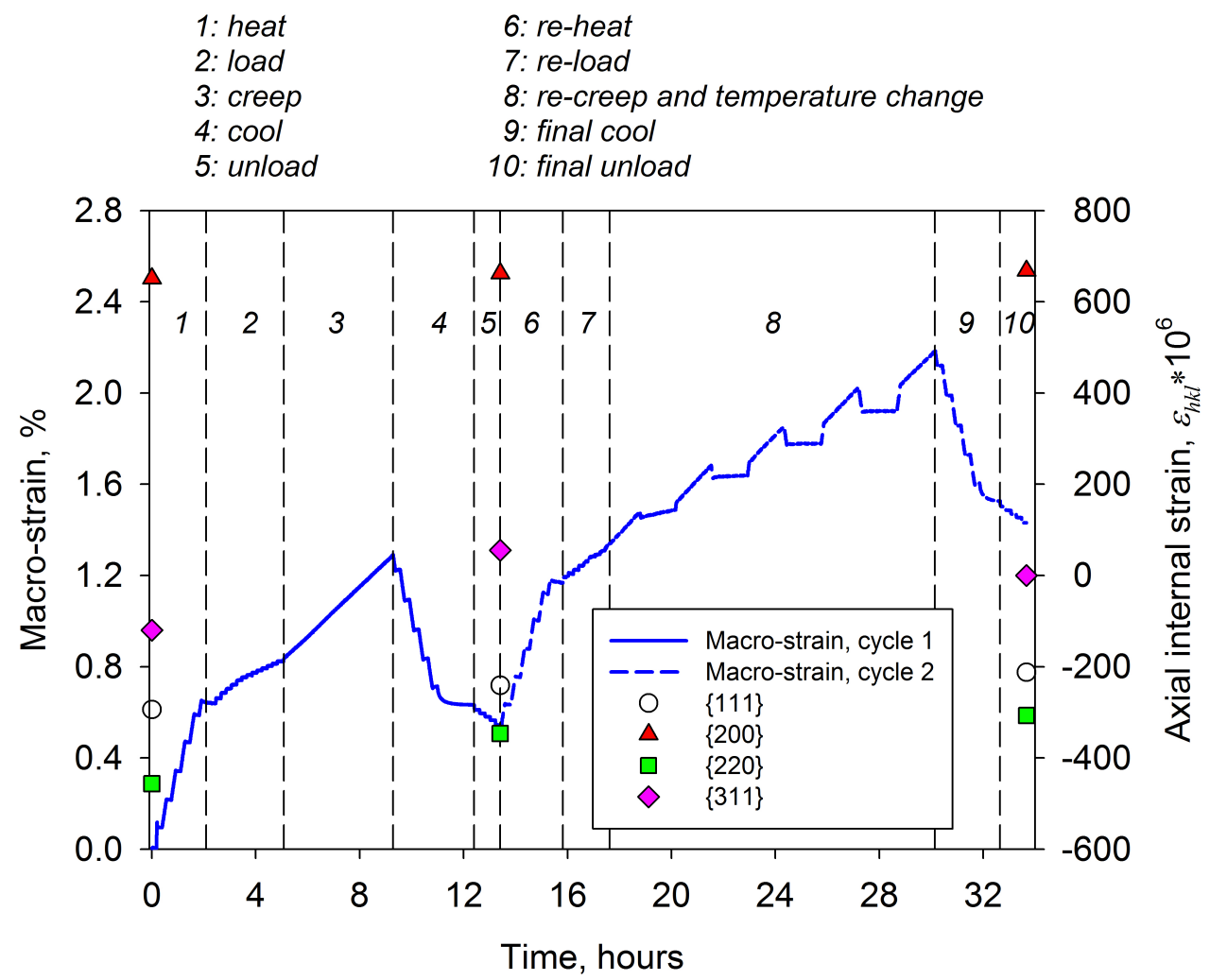

(b)

Figure 3: (a) Axial internal strain introduced by $1000 \mathrm{~h}$ creep pre-strain; (b) changes of macro-strain and axial internal strain for cycles 1 and 2 of Figure 2. 


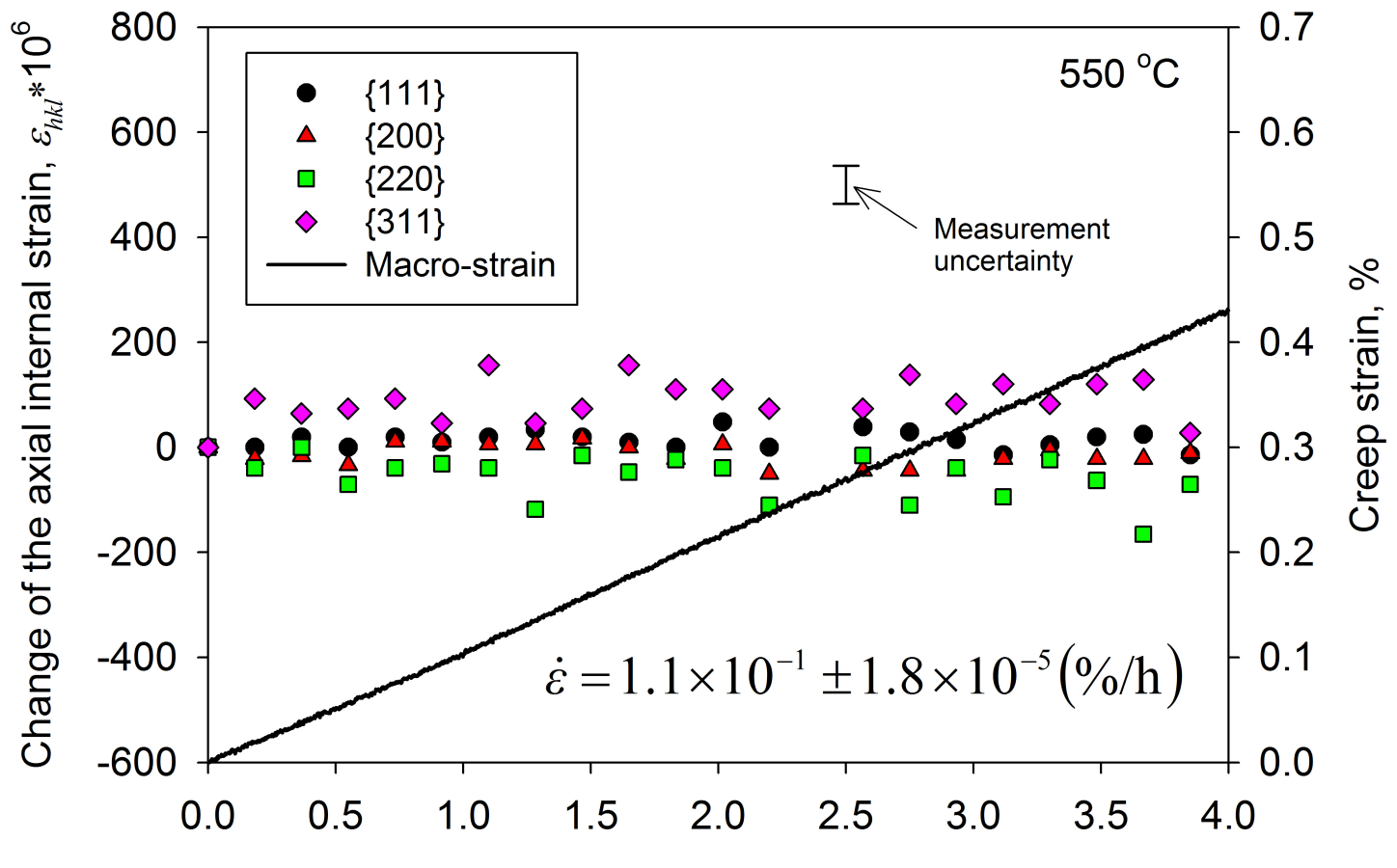

Creep time, hours

(a)

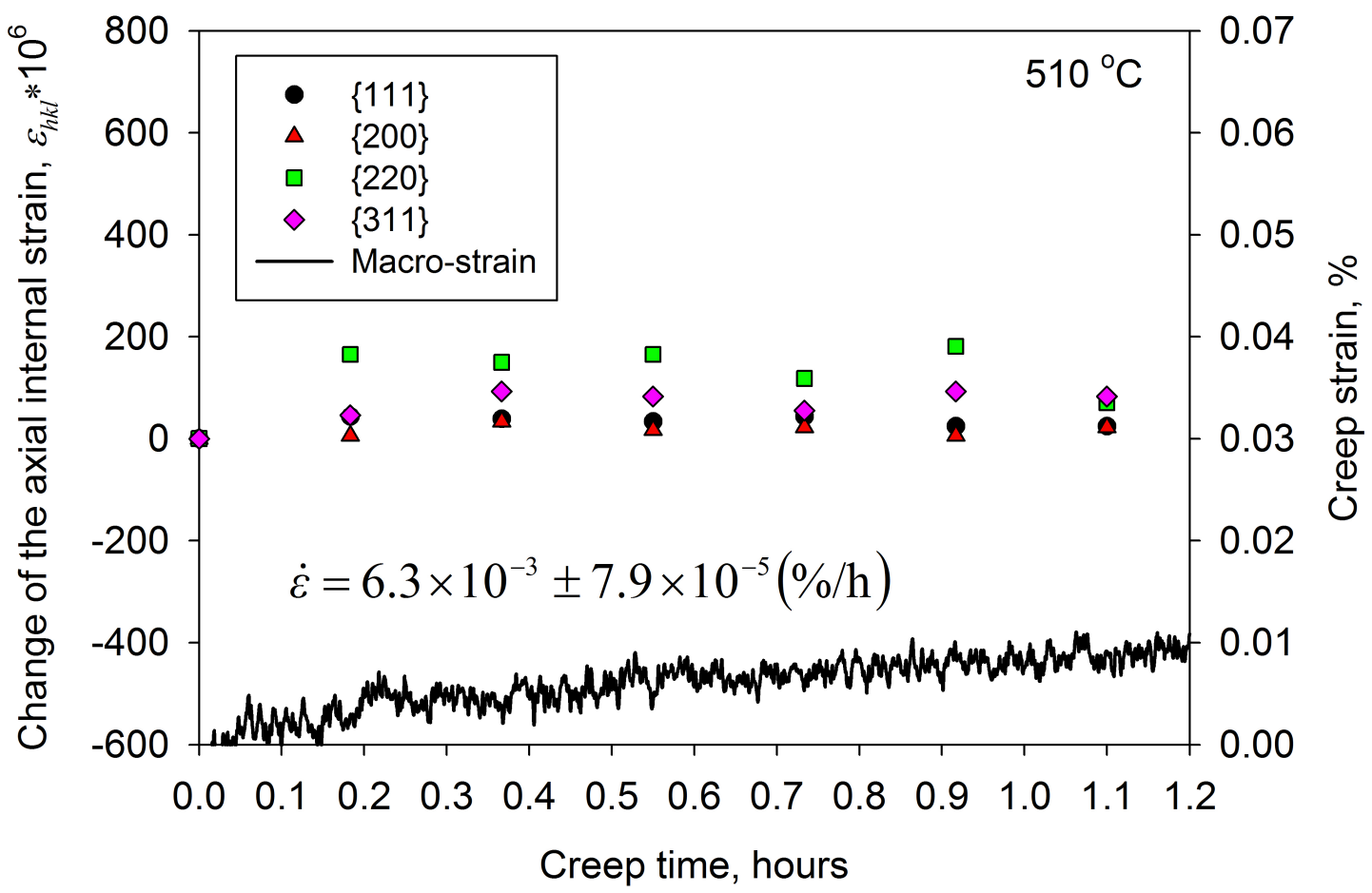

(b)

Figure 4: Evolution of internal strain and macro-strain during in-situ creep deformation of specimen 2 during different dwell steps of Figure 2 (b): (a) step 3 $550^{\circ} \mathrm{C}$; (b) step $8-510{ }^{\circ} \mathrm{C}$; (c) step $8-470{ }^{\circ} \mathrm{C}$; (d) end of step $8-550{ }^{\circ} \mathrm{C}$. Note: The measurement uncertainty for internal strain has been indicated in Figure 4 (a). In-situ creep was carried out at a constant stress of $250 \mathrm{MPa}$. 


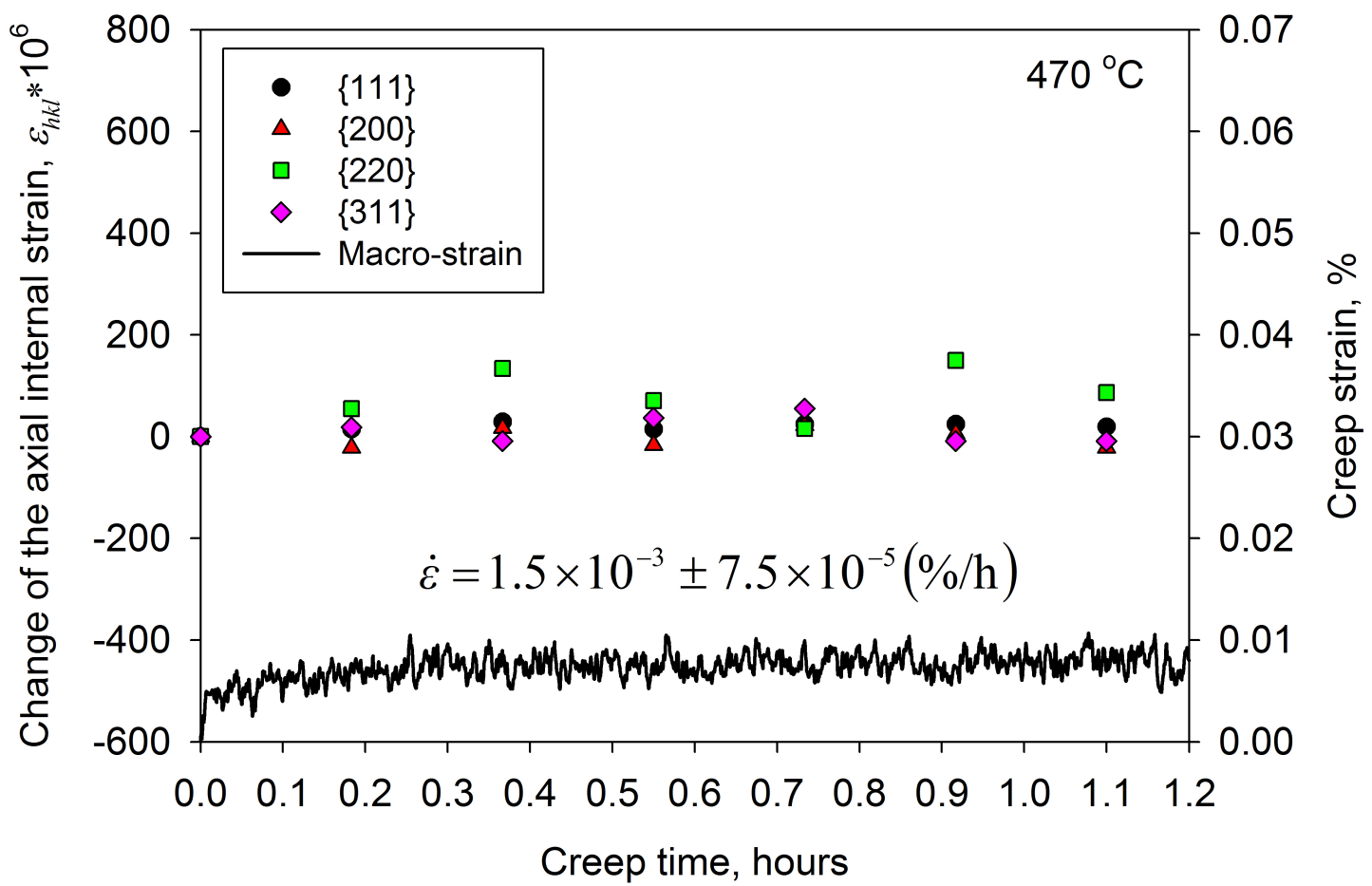

(c)

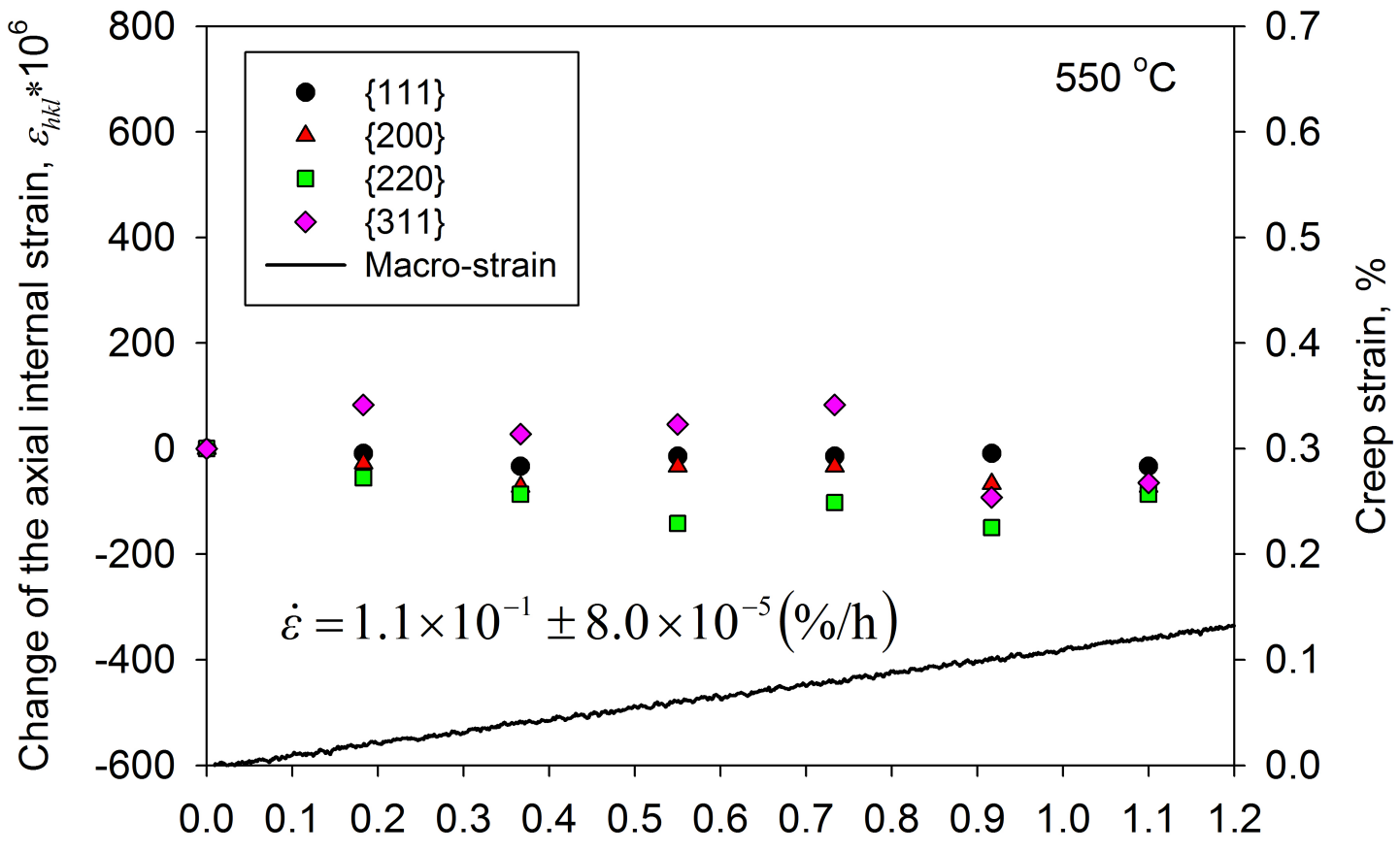

Creep time, hours

(d)

Figure 4 (CONTINUED) 


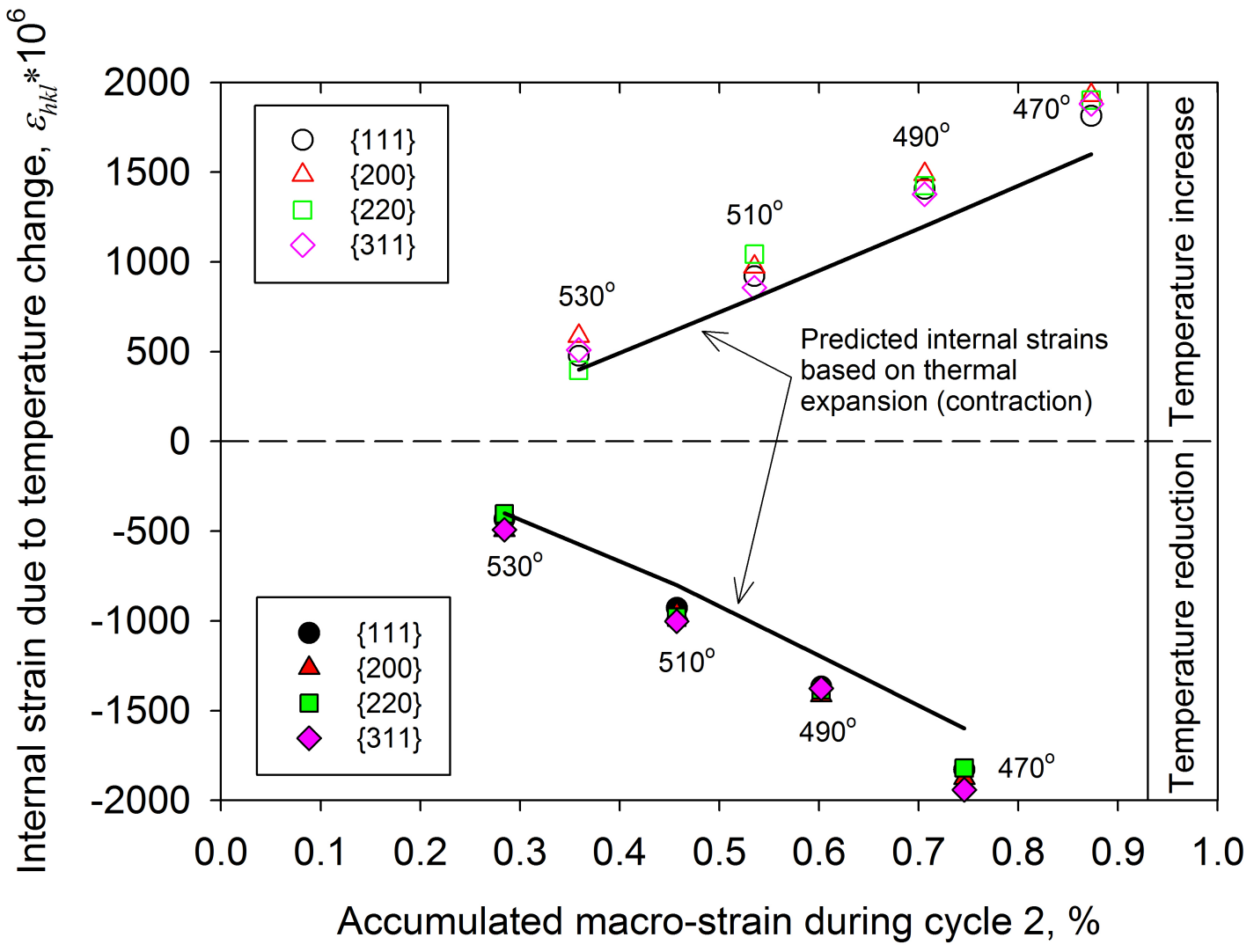

Figure 5: Internal strain changes (measured and predicted) due to temperature change as a function of the accumulated macro-strain during cycle 2 of Figure 2 (b).
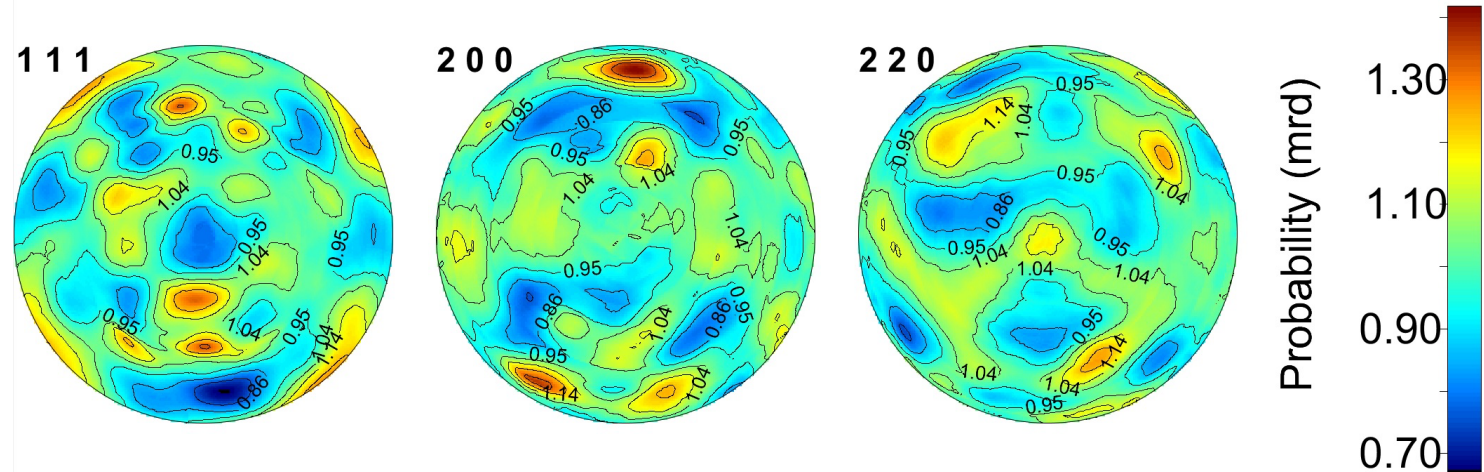

Figure 6: Crystallographic texture was measured on a creep pre-strained Type $316 \mathrm{H}$ austenitic stainless steel specimen using GEM instrument at ISIS neutron source, showing a weak texture for $\{111\},\{200\}$ and $\{220\}$ crystallographic orientations. Note: this specimen was creep tested for $60 \mathrm{~h}$ at $550{ }^{\circ} \mathrm{C}$ and $250 \mathrm{MPa}$, which produced a plastic pre-strain of $3.2 \%$ and a creep pre-strain of $1.1 \%$. 